\title{
Correction to: A Two-Parametric Model for Gas Flow in Low-Permeable Porous Materials
}

\section{Peter Paulini $^{1}$}

Published online: 2 March 2019

(c) Springer Nature B.V. 2019

\section{Correction to: Transport in Porous Media https://doi.org/10.1007/s11242-019-01245-7}

The original publication of the article includes the error in Fig. 9 legend. The correct Fig. 9 legend should be read as "Velocity exponent versus applied pressure gradient for all test data in Table 1".

Publisher's Note Springer Nature remains neutral with regard to jurisdictional claims in published maps and institutional affiliations.

The original article can be found online at https://doi.org/10.1007/s11242-019-01245-7.

$凶$ Peter Paulini

peter.paulini@aon.at

1 Material Technology, University Innsbruck, Innsbruck, Austria 